REVISTA DE DERECHO UNED, núm. 4, 2009

\title{
DE LA ARBITRARIEDAD ADMINISTRATIVA, CON ESPECIAL REFERENCIA AL ÁMBITO PENAL*
}

\author{
Sonia Calaza LóPEZ \\ Profesora Titular acreditada de Derecho Procesal de la UNED \\ Lucía Pedreño Navarro \\ Abogado del Estado.
}

La forma es hermana gemela de la libertad y enemiga jurada de la arbitrariedad.

Todo hombre tiene el deber de pisotear, cuando llega la ocasión, la cabeza de esa víbora que es la arbitrariedad y la ilegalidad.

(R. vON IHERING, «La lucha por el Derecho»).

Resumen: Este trabajo versa sobre la recepción del concepto arbitrariedad en la evolución de la Jurisdicción Contencioso-Administrativa española, acompañada de un estudio específico en materia penal.

Palabras clave: Arbitrariedad. Jurisdicción Contencioso-administrativa.

Abstract: The present paper deals with reception of the arbitrariness concept in the evolution of the Contentious-Administrative Spanish Jurisdiction, with a specific investigation in criminal matter.

* Este trabajo ha sido realizado en el marco del Proyecto de Investigación del Ministerio de Ciencia e Innovación, sobre la reforma de la Justicia Penal, con referencia SEJ 2007-62039, del que es investigador principal, el Prof. Vicente Gimeno Sendra (Catedrático de Derecho Procesal de la Universidad Nacional de Educación a Distancia). 
Key words: Arbitrariness concept. Contentious-Administrative Jurisdiction.

Sumario: 1. Introducción.-2. La instauración de la Jurisdicción Contencioso-Administrativa.-3. La Ley Santamaría de Paredes de lo contencioso-administrativo de 13 de septiembre de 1888.-4. El Fuero de los Españoles de 17 de julio de 1945.-5. La Ley de Régimen Jurídico de Administración del Estado de 26 de julio de 1957.-6. La Ley de Jurisdicción contencioso-administrativa de 27 de diciembre de 1956.-7. La Constitución española de 29 de diciembre de 1978.-8. La Ley 29/1998, reguladora de la Jurisdicción Contencioso-administrativa.-9. La arbitrariedad administrativa en el ámbito penal.

\section{INTRODUCCIÓN}

La arbitrariedad se remonta al comienzo de la vida en sociedad. Desde siempre y, en cierto modo, por la propia naturaleza humana, quién goza de poder puede caer en la tentación de excederse en su uso, esto es, de abusar de él.

Como es sabido, en el Antiguo Régimen no había una distribución de funciones. Así, puede afirmarse que no existía una delimitación de ámbitos de actuación en la lucha por el Derecho, en el largo y siempre inacabado camino hacia la consecución de la Justicia. Ello unido a la pluralidad de jurisdicciones existentes ${ }^{1}$ daba lugar a que se produjesen numerosas situaciones de desigualdad, discriminación e injustificados privilegios.

Las primeras manifestaciones jurídicas de la lucha contra la arbitrariedad se encuentran en el largo y dificultoso proceso de formación de la Jurisdicción Contencioso-Administrativa, referidas, en un principio, específicamente a los abusos de poder cometidos por la propia Administración.

La Constitución de Cádiz de 1812 tratará de solventar esta situación consagrando el principio de unidad de fuero jurisdiccional, con la explícita pretensión de que dicho principio suponga un freno a las ac-

${ }^{1}$ La situación descrita en el texto ha sido considerada por NIETO, A., como «caótica y justificada, en principio, por la dificultad técnica de que un solo Magistrado dominase las especialidades de cada materia jurídica, en cuya realidad no es difícil entrever un trasfondo de privilegios y de exenciones para ciertas clases y personas, tal como nos pinta, en abundantes testimonios, la literatura de la época», en "Los orígenes de lo contencioso administrativo en España», RAP n. ${ }^{\circ}$ 50, 1966, p. 28. 
tuaciones arbitrarias a que antes hemos hecho referencia, lo que producirá, por toda consecuencia, que todos los asuntos (con excepción de los militares y eclesiásticos) pasen a ser enjuiciados por los Tribunales ordinarios, suprimiéndose al fin los Tribunales de privilegio ${ }^{2}$.

A partir de este momento, de los asuntos comunes, civiles y criminales conocerán los Tribunales ordinarios; de los asuntos administrativos, se ocupará la propia Administración y, por lo que respecta a los contencioso-administrativos, nos encontramos ante una "peligrosa zona de nadie» en afortunada expresión de $\mathrm{Nieto}^{3}$. De la última voluntad del Monarca dependerá, pues, el que, ante un litigio concreto en el que entran en juego, tanto intereses civiles, como administrativos, entienda un Tribunal judicial o la propia Administración; con lo que, al encontrarse en una sola mano la posibilidad de administrar y juzgar, era lógicamente muy difícil conseguir un justo equilibrio en el reparto del poder, dando lugar, en muchas ocasiones, a soluciones basadas únicamente en criterios de oportunidad ${ }^{4}$, tachados hoy día por ese mismo motivo, de arbitrarios.

El criterio determinante a la hora de conceder legitimidad a la Administración para juzgar sus propias actuaciones responde a argumentaciones tan variadas como lo son la necesaria rapidez en la resolución de los intereses jurídicamente quebrantados, el profundo conocimiento de sus propias actuaciones, la absoluta creencia en la necesidad de que los intereses particulares cedan, en caso de conflicto, en favor de los generales; la ausencia de rencores o utilización de prácticas astutas hacia el otro litigante, lo que dota de mayor trans-

${ }^{2}$ En este sentido, la Exposición de Motivos, dando buena muestra de una clara toma de conciencia respecto a la necesidad de comenzar una encarecida lucha contra la arbitrariedad, afirma que «La Comisión no necesita detenerse a demostrar que una de las principales causas de la mala administración de justicia entre nosotros es el fatal abuso de los fueros privilegiados introducidos para ruina de la libertad civil y oprobio de nuestra antigua y sabia Constitución. El conflicto de autoridades que llegó a establecerse en España en el último reinado, de tal modo había anulado el imperio de las leyes, que casi parecía un sistema planteado para asegurara la impunidad de los delitos».

${ }^{3}$ NIETO, «Los orígenes de lo contencioso-administrativo en España», cit., p. 31.

${ }^{4}$ Así, tal y como señaló NIETO, A., «en el Derecho constitucional español, a diferencia del francés, no existe una oposición forzada, una alternativa entre el Poder Judicial y el Poder administrativo, sino que, por encontrarse ambos bajo la suprema autoridad del Monarca, corresponde a éste decidir libremente, y por razones de oportunidad, a cuál de las dos Organizaciones - a la Judicial o a la Administrativaconviene entregar el conocimiento de las cuestiones administrativas», en «Los orígenes de lo contencioso-administrativo», cit., p. 34. 
parencia al proceso y, ante todo, el generalizado respeto a la libertad de actuación de la Administración, que impedía a los autores de la época considerar algo bueno todo lo que supusiese obstáculos, trabas o limitaciones a la misma.

La Administración persigue la consecución del bien general y es garante de los intereses generales, a diferencia de los Tribunales judiciales, que procuran la consecución de la justicia mediante la defensa de los intereses particulares y esto hace que sea muy difícil establecer un equilibrio que permita la satisfacción de los primeros, sin quebrantar la protección individual de los segundos, cuando, pese a proclamar la Constitución de 1812 el principio de separación de poderes, no responde la realidad jurídica a un equitativo reparto de poder.

La Administración, por tanto, resolvía las reclamaciones realizadas por los particulares contra sus propios actos, con lo que estaba siendo Juez y parte, en una misma relación de conflicto y ello daba lugar a una absoluta carencia de objetividad.

\section{LA INSTAURACIÓN DE LA JURISDICCIÓN CONTENCIOSO-ADMINISTRATIVA}

Parada Vázquez 5 entiende que la Jurisdicción administrativa o Administración contenciosa nace como una respuesta o alternativa obligada frente a la incompetencia de los Tribunales para los litigios en que es parte la Administración, respondiendo a la idea y a la técnica de los fueros privativos.

A imitación del sistema francés, que, con medio siglo de antelación al español, en el más puro respeto al principio de división de poderes, se muestra contrario a la invasión de funciones de unos en otros, atribuyendo a la Administración la judicialización de sus propios actos, se creará en España un Consejo Real, por Ley de 6 de septiembre de 1845, Reglamento de 30 de diciembre de 1846, así como unos Consejos Provinciales, por Ley de 2 de abril de 1845, Reglamento de 1 de octubre de $1845^{6}$, que sufrirán dos interrupciones de-

${ }^{5}$ Vid., PARADA VAZQUEZ, R., "Privilegio de decisión ejecutoria y proceso contencioso", RAP n. ${ }^{\circ} 55,1968$, p. 73.

${ }^{6}$ Este momento constituye el verdadero nacimiento de la Jurisdicción contencioso-administrativa en España y ofrece, a los particulares, una triple vía de protección de sus derechos jurídicamente quebrantados. En este sentido, NIETO, A., hace referencia a la Revista «El Derecho Moderno», tomo XII, 1852, p. 200, en la que se espe- 
bido al bienio progresista (1854-1856) y a la Revolución de $1868^{7}$. En la etapa intermedia (1856-1868) el Consejo Real pasará a ser reorganizado por Real Decreto de 14 de julio de 1858, que le dará la actual denominación de Consejo de Estado, y será finalmente restablecido por el Decreto-Ley del Ministerio-Regencia, de 20 de enero de 1875, dotando, a las Comisiones provinciales, de las competencias anteriormente asumidas por los Consejos Provinciales, y en cuyo preámbulo manifiesta las razones en que se apoya: "Lo contenciosoadministrativo es un discreto medio de poner freno a la arbitrariedad ministerial, sin menoscabar los fueros del Gobierno del Estado: su establecimiento produjo sazonados frutos, y fue tan bien acogido por la opinión pública, que aun cuando en 1845 se suprimió el Consejo Real, se reconoció la necesidad de crear un Tribunal especial que conociese en lugar suyo de las demandas contra las providencias gubernativas. Restablecido aquel alto cuerpo en 1856, volvió a entender en los asuntos contencioso-administrativos con tan notorio acierto, que sus decisiones cada día cobraban más autoridad y ejercían más influjo en la interpretación y aplicación de las Leyes que regulan los diversos ramos de los servicios públicos».

Así, pues, en este momento histórico, los titulares de la Administración activa tenían encomendada la función de aplicar las leyes, desarrollarlas reglamentariamente y ejecutarlas cuando no hubiese una conflictiva oposición entre los derechos particulares y la consecución de los intereses generales a los que la propia Administración debe servir. En este sentido, la más autorizada doctrina ${ }^{8}$ subraya que «la Administración activa sólo tendría, pues, Jurisdicción volun-

cifica esta pluralidad de vías de la siguiente manera: "Para reformar los actos injustos o arbitrarios de la Administración y poner los derechos de los particulares a cubierto de los perjuicios que pudieran causarles la ignorancia o la mala fe de los funcionarios administrativos, con providencias ilegales en el fondo o en la forma, han establecido las Leyes los recursos convenientes ante el superior jerárquico en la línea administrativa activa, y ante los Tribunales ordinarios, por la vía contenciosa, cuando se alega que hay derechos vulnerados. Y si todavía envolviese la declaración alguna cuestión de propiedad, tendría expedita el perjudicado su acción ordinaria ante los Tribunales», «Los orígenes de lo contencioso-administrativo», cit., p. 42.

${ }^{7}$ Durante el bienio progresista, serán suprimidos los Consejos Provinciales, por los Reales-Decretos de 7 de agosto de 1845, los Consejos Provinciales, pasando sus competencias a manos de las Diputaciones provinciales y, en sustitución del Consejo Real, se creará un Tribunal contencioso-administarativo. El segundo paréntesis (18681875) dará lugar a que, por los Decretos de 13 y 16 de octubre y de 26 de noviembre de 1868, ocupen el lugar del Consejo de Estado, las Salas especiales del Tribunal supremo y el de los Consejos provinciales, las Audiencias Nacionales.

${ }^{8}$ Vid., por todos, PARADA VAZQUEZ, J.R., "Privilegio de decisión ejecutoria y proceso contencioso", n. ${ }^{\circ} 55$ de la RAP, 1968, p. 77. 
taria, sólo puede actuar y ejecutoriar válidamente sus decisiones si media el asentimiento de los sujetos afectados».

En otro plano de actuación completamente diferente, se encontraban los órganos de la Administración contenciosa, cuya competencia se predicaba de la ejecución de las Leyes en supuestos conflictivos.

Las actuaciones realizadas por la Administración activa serán debidamente enjuiciadas por la Jurisdicción contencioso-administrativa, cuyo efectivo conocimiento precisa, según un sector de la doctrina ${ }^{9}$, de "la existencia de ese acto administrativo previo», siendo necesario, además, que esta actuación «haya infringido un derecho preexistente del particular» para que aquella Jurisdicción entre conocer el fondo del asunto. Un segundo sector de la doctrina ${ }^{10}$, sin embargo, entiende que el acto previo del «Jefe Político» no es necesario, con carácter general, para acceder a la vía contenciosa.

En un caso u otro, en cuanto a lo que a la problemática en curso de análisis atañe, la discrecionalidad no es todavía susceptible del debido enjuiciamiento, por lo que, la inmunidad judicial, respecto a los posibles excesos administrativos determinantes de soluciones arbitrarias, continúa estando presente ${ }^{11}$; todo ello sin obviar el debido reconocimiento al avance supuesto por el nacimiento de la Jurisdicción contencioso-administrativa, en orden al efectivo control de los conflictos suscitados entre particulares, como consecuencia de los efectos perjudiciales causados por la elaboración o desarrollo de un acto administrativo contrario a sus intereses legítimos, o entre estos y la propia Administración, en el caso de que esta última haya otorgado prioridad a los intereses particulares a costa de una lesión en la realización de los generales.

\footnotetext{
${ }^{9}$ NIETO, A., «Sobre la tesis de Parada en relación con los orígenes de lo contencioso-administrativo", RAP n. ${ }^{\circ}$ 57, 1968, p. 31.

${ }^{10}$ En este sentido, PARADA VÁZQUEZ, J.R., ha señalado que «el Consejo Real admite con toda claridad que en unos casos la Administración activa debe resolver previamente, pero que en otros el asunto es directamente contencioso», por lo que «la exigencia de esta decisión previa gubernativa se exige en el caso concreto, pero no se afirma como doctrina de carácter general», en «Réplica a Nieto sobre el privilegio de decisión ejecutoria y el sistema contencioso-administrativo», RAP n. ${ }^{\circ}$ 59, 1969, p. 53.

${ }^{11}$ PARADA VÁZQUEZ, J. R., entiende que la exención jurisdiccional de la discrecionalidad administrativa radica en que «toda la actuación administrativa de ejecución voluntaria de las leyes se manifiesta en actos reglamentarios o actuaciones singulares sin oposición jurídica», en «Privilegio de decisión ejecutoria y proceso contencioso», cit., p. 78.
} 


\section{LA LEY SANTAMARÍA DE PAREDES DE LO CONTENCIOSO- ADMINISTRATIVO DE 13 DE SEPTIEMBRE DE 1888}

La Ley Santamaría de Paredes de lo contencioso-administrativo, de 13 de septiembre de 1888, establecerá un sistema mixto o armónico de Jurisdicción mediante la creación de un Tribunal especial de lo contencioso-administrativo, que formará parte del Consejo de Estado, pasando a convertirse en una sección del mismo con Jurisdicción delegada por Ley de 22 de junio de 1894, para ser definitivamente integrado en la Sala especial del Tribunal Supremo por Ley de 5 de abril de 1904.

La referida Ley de 13 de septiembre de 1888 tiene como principal objetivo, expresamente reconocido en su Exposición de Motivos, suprimir la Jurisdicción retenida, lo que supone un importante triunfo de los autores progresistas de la época que luchaban por la judicialización de la Administración, cobrando su impulso original de las ideas revolucionarias que, en el largo recorrido hacia el definitivo asentamiento del sistema contencioso-administrativo actual, constituyen uno de los primordiales fundamentos de la lucha contra la arbitrariedad.

A pesar de este reconocido avance, la Ley Santamaría de Paredes de lo contencioso-administrativo de 1888 (que permanecerá intacta a través de sus refundiciones de 1895 y 1952 hasta la entrada en vigor de la Ley reguladora de la Jurisdicción contencioso-administrativa de 27 de diciembre de 1956) excluía del control judicial todos los actos administrativos dictados en el ejercicio de una potestad discrecional, y entendía que la Administración obraba en el ejercicio de sus facultades regladas en la medida en que debía acomodar sus actos a disposiciones de una ley, de un reglamento o de otro precepto administrativo - según predicaba el artículo 2 de la mencionada Ley-con lo que la libertad de la Administración gozaba de una total inmunidad judicial puesto que la discrecionalidad existía siempre que no se presentase norma aplicable al caso.

Un inconveniente añadido a esta nueva dicotomía entre lo discrecional y lo reglado, a efectos de su posible judiciabilidad, venía determinado por el extremado respeto del Tribunal Supremo a la hora de enjuiciar los asuntos en los que presuntamente la Administración se había extralimitado, lo cual entorpecía enormemente la deseada consecución de la Justicia. En este sentido se pronuncia la doctrina ${ }^{12}$

${ }^{12}$ GARRIDO FALLA, F., "La evolución del recurso contencioso administrativo en España», RAP n. ${ }^{\circ}$ 55, 1968, p. 21. 
de la época al afirmar que «la jurisprudencia contencioso-administrativa de nuestro Tribunal Supremo no se ha caracterizado durante más de medio siglo (y salvo contadas excepciones) por su progresismo; antes bien, su examen invita a sospechar que el Alto Tribunal ha usado con excesiva prudencia de sus prerrogativas, quizá pensando que esta era la mejor vía para conservarlas frente a un Poder ejecutivo que siempre ha tenido en sus manos la posibilidad de arrebatárselas haciendo aprobar el oportuno proyecto de ley».

\section{EL FUERO DE LOS ESPAÑOLES DE 17 DE JULIO DE 1945}

La primera manifestación positiva concreta de la que tenemos constancia, a propósito del concepto arbitrariedad, es la recogida en el artículo 17 del Fuero de los Españoles de julio de 1945 (modificado por la Ley Orgánica del Estado de 10 de enero de 1967) al establecer «Todos los órganos del Estado actuarán conforme a un orden jerárquico de normas establecidas que no podrán arbitrariamente ser interpretadas ni. alteradas».

Este concepto de "alteración arbitraria» no puede entenderse, según ha estimado un autorizado sector de la doctrina clásica ${ }^{13}$, más que como un límite al ejercicio de la potestad reglamentaria, por dónde puede introducirse toda la técnica sustancial de control sobre el concepto de arbitrariedad.

Ahora bien, así como la «interpretación arbitraria» se refiere, de un lado, al plano de la aplicación legal, la «alteración arbitraria» no puede aludir más que al plano de la creación normativa, y afecta, por tanto, como un límite sustancial, al ejercicio de la potestad reglamentaria. De otro lado, por este mismo precepto se impone sin esfuerzo la vinculación del Reglamento, no sólo a la ley, sino también a las declaraciones constitucionales materiales, jerárquicamente superiores ${ }^{14}$.

${ }^{13}$ GARCÍA DE ENTERRÍA, E., «¿Es inconveniente o inútil la proclamación de la interdicción de la arbitrariedad como principio constitucional? Una nota», RAP n. ${ }^{\circ}$ 123, 1991, p. 215.

${ }^{14}$ Vid., GARCÍA DE ENTERRÍA., E., «¿Es inconveniente o inútil la proclamación de la interdicción de la arbitrariedad como principio constitucional? Una nota», cit., p. 217. 


\section{LA LEY DE RÉGIMEN JURÍDICO DE ADMINISTRACIÓN DEL ESTADO DE 26 DE JULIO DE 1957}

La Ley de Régimen jurídico de Administración del Estado de 26 de julio de 1957 señala en su artículo 30 que «las resoluciones administrativas de carácter particular no podrán vulnerar lo establecido en una disposición de carácter general aunque aquellas tengan grado igual o superior a éstas». El contenido de este artículo coincide, de acuerdo con la doctrina, con el viejo principio legem patere quam fecisti (te vincula la ley que tú mismo hiciste), pero esta prohibición a los órganos de la Administración Pública de excepcionar — mediante actos administrativos singulares, para un caso concreto- la aplicación de las disposiciones de carácter general, va aún más allá puesto que (tal prohibición) alcanza, no solo a la autoridad de la que dimana la norma, sino a cualquier otra, incluso de superior jerarquía, regla ésta que procura evitar que se produzcan situaciones injustificadas de favor, en beneficio de personas determinadas, así como discriminaciones o distinciones arbitrarias» ${ }^{15}$.

Los titulares de la potestad reglamentaria, en el ejercicio de su actividad normativa, estarán sujetos, por tanto, no sólo a la letra de la Ley que habilita esta creación normativa, sino también a los dictados del propio Reglamento, de cuya existencia cobrarán validez los actos administrativos que integren su ámbito de aplicación y se hallen expresamente regulados, pudiendo, como es lógico, invalidarlo por entero o modificar los concretos preceptos que, en un momento posterior, estime inoperantes, pero nunca inaplicarlo, en todo o en parte, para casos singulares.

El contenido del fundamento de la inderogabilidad singular de los Reglamentos supone una clara excepción al principio maiore ad minus puesto que quién puede lo más - elaborar, modificar o derogar el contenido reglamentario-, no puede lo menos - obviar la observancia del contenido normativo por él mismo creado para casos singulares- y ello tanto si contiene consecuencias beneficiosas para los particulares (constituyendo en este caso su inaplicación, una discriminación) o coercitivas (constituyendo entonces, a sensu contrario, un privilegio).

Esta excepción encuentra, en mi opinión, su justificación en el propio contenido de la discrecionalidad administrativa, como potes-

${ }^{15}$ Vid., GARCÍA DE ENTERRÍA, E. y FERNÁNDEZ, T.R., "Curso de Derecho Administrativo», Ed. Civitas, 4. ${ }^{\text {a }}$ ed, Madrid, 1982, p. 183. 
tad absolutamente necesitada de una previa atribución legal. Efectivamente, la Administración podrá, mediante la elaboración normativa que legalmente le está conferida en virtud de su potestas reglamentaria, crear Derecho objetivo, mas su singularidad, con respecto al ámbito de actuación legislativo del que manan leyes formales, integrantes en igual medida del Ordenamiento Jurídico, no consiste tanto en la obligada observancia del contenido de las mismas, como en los límites que conlleva su imperativa sujeción a la letra de aquellas.

En este sentido, entenderá la doctrina ${ }^{16}$ que es precisamente en la diferencia de planos en que una y otra actuación se sitúan - y consiguiente posibilidad de excepcionar o no, para determinados casos, la efectiva aplicación de lo dispuesto en sus respectivos preceptosdonde se apoyan y justifican el principio de la inderogabilidad singular de los reglamentos. Concretamente, manifiesta éste que «la derogación general es posible porque emana de una potestad modificativa del Ordenamiento - la potestad reglamentaria-, que la Administración tiene atribuida en términos formales. En cambio, para ir en un caso concreto en contra de un Reglamento general, la Administración no tiene potestad porque es el propio Reglamento el que atribuye, en los límites que su régimen establezca, la potestad de actuar en la materia que regula, y es manifiestamente una ilegalidad tratar de utilizar esta potestad para contravenir el propio Reglamento. El mismo argumento de la falta de potestad sirve para explicar por qué una autoridad superior no puede ir singularmente contra el Reglamento dictado por autoridad inferior».

Sin embargo, la situación relativa a que en el propio Reglamento se legitime la excepción parece apartarse sustancialmente de la interdicción supuesta por el principio que nos ocupa, puesto que, perfectamente, puede la voluntad administrativa, en consciente ejercicio normativo, determinar de forma razonable tal posibilidad, sin por ello caer en el vicio de la arbitrariedad.

La consecuencia resultante de entender reducida la competencia administrativa a la creación formal de Derecho objetivo sin concederle, paralelamente, la posibilidad de modificar - siempre con carácter general y entendiendo por tal generalidad la efectiva solución de que afecte por igual a cuántos particulares se vean por ella afectados para que no suponga discriminación alguna- para concretos

${ }^{16}$ GARCÍA DE ENTERRÍA, E., «Observaciones sobre el fundamento de la inderogabilidad singular de los Reglamentos», RAP n. ${ }^{\circ} 27,1958$, p. 83. 
supuestos de hecho las disposiciones reglamentarias, supondría una anulación injustificada del ámbito de discrecionalidad administrativa, en base a un razonamiento contra legem.

Así, pues, no parece constitutiva de manifestación infractora alguna (y por tanto arbitraria) en materia de inderogabilidad singular de los reglamentos, la consecuencia resultante de modificar concretas disposiciones normativas para casos determinados sino, como con total rigor ha precisado la doctrina ${ }^{17}$, la consistente en "resolver singularmente contra un Reglamento, cuyos preceptos generales continúan vigentes, porque entonces no se ejercita la potestad reglamentaria, sino potestades de resolución material y, por ende, concretadas en los propios términos que tal reglamento ha definido y cuyo extravase, mucho más la franca contradicción implica una ilegalidad notoria».

Este principio ha sido entendido en igual sentido por un segundo sector de la doctrina ${ }^{18}$, en virtud de cuyos estudios puede subrayarse que éste no supone la prohibición de reglamentos singulares, que «son admisibles en tanto no vulneren el principio de igualdad ante la ley», ni mucho menos, la interdicción relativa a que «el propio reglamento pueda autorizar a la Administración a dispensar de su observancia en casos concretos; hipótesis que es también admisible, salvo prohibición legal expresa».

El Profesor García de Enterría ${ }^{19}$ fue, sin embargo, el primer autor que habló en España de un principio de interdicción de la arbitrariedad de los poderes públicos oponible a la Administración, como un límite a su libertad de actuación, en un artículo publicado en 1959 bajo el título "La interdicción de la arbitrariedad en la potestad reglamentaria», en el que, tras realizar un pormenorizado análisis de las

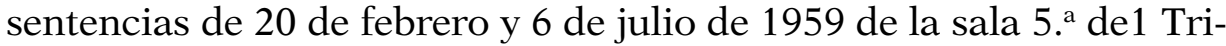
bunal Supremo, señala la existencia de un importante giro conceptual consistente en la construcción de un límite material a la potestad reglamentaria (la interdicción de la arbitrariedad) con independencia de los límites puramente formales, que caracterizaban de ilimitado al poder reglamentario, fuera de los casos de contradicción con precepto superior o de invasión de materia reservada a la ley, según el artículo 26 de la Ley de Régimen jurídico de Administración del Estado.

${ }^{17}$ GARCÍA DE ENTERRÍA, «Observaciones sobre el fundamento de la inderogabilidad singular de los reglamentos», RAP n. ${ }^{\circ} 27,1958$, p. 84.

18 SANTAMARÍA PASTOR, J. A., "Principios de Derecho Administrativo», Ed. CEURA, Madrid, 1990, p. 263.

${ }^{19}$ GARCÍA DE ENTERRÍA, E., «La interdicción de la arbitrariedad en la potestad reglamentaria», RAP n. ${ }^{\circ}$ 30, 1959, p. 136. 
García de Enterría ${ }^{20}$ precisará, ya en 1959, con total rigor, los supuestos comprendidos bajo el concepto de la arbitrariedad reglamentaria, en la siguiente enumeración: «Reglamentos que partan de una apreciación falsa de los hechos en virtud de los cuales se determinen, que implique una ruptura del principio de igualdad, que pretendan transgredir los principios inmanentes a la naturaleza de instituciones cuya configuración transciende de los poderes reglamentarios, que intenten establecer un régimen restrictivo que no guarde proporción o congruencia con las finalidades positivas perseguidas, que suponga una manipulación de los medios esenciales de vida de los destinatarios como instrumentos coercitivos, que aparezcan motivados en una finalidad de proyección de simples intereses particulares, para cuya elevación al rango de intereses públicos no se reconoce un poder soberano a la calificación reglamentaria» y aún entiende que el principio de interdicción de la arbitrariedad reglamentaria no se agota en estas formulaciones jurisprudenciales puesto que «la fecundidad del principio, que es uno de los rasgos fundamentales de todo autentico principio general (...) encierra virtualidades y potencialidades que no dudamos que el Tribunal Supremo seguirá obteniendo y proclamando. Precisamos únicamente alguna de las más claras, y quizá también de las más atractivas (...) vulneración por un Reglamento de los derechos fundamentales, concepciones esenciales y "principios del Movimiento Nacional», declarados en las llamadas Leyes fundamentales o constitucionales...; Reglamentos que pretendan tener un efecto retroactivo; Reglamentos que aboquen a resultados «manifiestamente injustos» $\mathrm{O}$ «iniquidad manifiesta», o atenten a la «justicia natural»; Reglamentos intrínseca $\mathrm{u}$ objetivamente que notoriamente falten a la buena fe exigible en la relación poder público-subditos, o a los criterios o standars de buena administración, o que por la magnitud e importancia de sus efectos haya que reservar al dominio de la ley formal, requiriendo al menos una habilitación legal específica, etc.

Un sector de la doctrina contemporánea ${ }^{21}$ ha venido a manifestar que una de las proyecciones del principio de interdicción de la arbitrariedad la constituye la repugnancia que ocasiona al principio de seguridad jurídica. Pero la verdadera originalidad de la inderogabilidad singular de los reglamentos (que constituye la más relevante mani-

${ }^{20}$ GARCÍA DE ENTERRÍA, E., «La interdicción de la arbitrariedad en la potestad reglamentaria», RAP n. ${ }^{\circ}$ 30, pp. 161 a 165.

${ }^{21}$ ALZAGA VILLAAMIL, O., «Derecho político español según la Constitución de 1978», Ed. Edersa, Madrid, 1996, p. 179. 
festación positiva del principio que nos ocupa y que reitera el artículo 50 en su párrafo segundo de la actual Ley de Régimen jurídico de las Administraciones Públicas y del Procedimiento administrativo común de 27 de noviembre de 1992) radica en la posibilidad de que determinados particulares encuentren excesivas facilidades por parte de las Administraciones Públicas que estuviesen dispuestas a derogar, en beneficio de ellos, los trámites y regulaciones que se exigen con carácter general a todos los ciudadanos, dando lugar con ello a una desigualdad de trato cuando las circunstancias o situaciones son objetivamente similares a las de las personas que sufrieron la discriminación o distinción arbitraria ${ }^{22}$. Otra faceta de la interdicción de la arbitrariedad viene determinada, según el sector de la doctrina ${ }^{23}$ a que me he referido anteriormente, por el principio de igualdad de trato en cuánto que otorga un valor de compromiso para la Administración a los propios precedentes que la misma ha venido sentando en actuaciones previas, aunque las mismas se hayan desenvuelto en el ámbito de la discrecionalidad administrativa.

\section{LA LEY DE JURISDICCIÓN CONTENCIOSO- ADMINISTRATIVA DE 27 DE DICIEMBRE DE 1956}

La más interesante novedad la constituye la Ley de Jurisdicción contencioso-administrativa, de 27 de diciembre de 1956, puesto que los actos discrecionales de la Administración dejan de estar excluidos de la fiscalización contencioso-administrativa y se regula por vez primera en nuestro Derecho la técnica de la desviación de poder.

En la propia Exposición de Motivos de esta Ley se explica, con total claridad, la significativa importancia jurídica del 1ibre ámbito de actuación administrativa, así como el alcance que conlleva su control, ambos extremos manifestados de la siguiente manera: «La determinación de su existencia está vinculada al examen de la cuestión de fondo, de tal modo que únicamente al juzgar acerca de la legitimidad del acto cabe concluir sobre su discrecionalidad; y, en fin, ésta surge cuando el Ordenamiento Jurídico atribuye a algún órgano competencia para apreciar, en un supuesto dado, lo que sea de interés público. La discrecionalidad, en suma, justifica la improcedencia,

${ }^{22}$ GARCÍA DE ENTERRÍA, E. y FERNÁNDEZ, T.R., «Curso de Derecho Administrativo», cit, p. 185.

${ }^{23}$ ALZAGA VILLAAMIL, O., "Derecho político español según la Constitución de 1978», cit., p. 179. 
no la inadmisibilidad, de las pretensiones de anulación, y aquella no en tanto el acto discrecional, sino en cuanto por delegar el Ordenamiento jurídico en la Administración la configuración según el interés público del elemento del acto de que se trata y haber actuado el órgano con arreglo a Derecho, el acto impugnado es legítimo».

La acogida doctrinal ${ }^{24}$ y la rápida e intensa interpretación y aplicación jurisprudencial, a propósito de esta nueva regulación de lo contencioso-administrativo, fueron extraordinariamente satisfactorias.

\section{LA CONSTITUCIÓN ESPAÑOLA DE 29 DE DICIEMBRE DE 1978}

A pesar del extraordinario avance que supuso la entrada en vigor de la Ley jurisdiccional de 1956, tal y como hemos constatado, en las exclusiones legales de fiscalización judicial de la discrecionalidad administrativa, quedaba, no obstante, todavía abierta una vía a la to-

${ }^{24}$ Sirvan, entre otras, como buena muestra de ello, las manifestaciones, entre otros, de los siguientes autores: Así, MOZO SEOANE, A.: «Es público y reconocido que entre tantos avances propiciados por la nueva legislación contencioso-administrativa, uno de los más importantes y decisivos fue el tratamiento dado al tema de la. discrecionalidad administrativa, por lo que supuso de definitiva y tajante reducción de uno de los llamados círculos de exención jurisdiccional o inmunidades de la Administración», en «La discrecionalidad de la Administración pública en España», Ed. MONTECORVO, Madrid, 1985, p. 180; VILLAR PALASÍ, J.L. y VILLAR EZCURRA, J.L.: «La ley es claramente judicialista, siguiendo la orientación que impuso la de 5 de abril de 1904, en cuanto confía la Jurisdicción contencioso-administrativa a verdaderos Tribunales encuadrados en la común organización judicial e integrados por Magistrados, profesionales, con los deberes e incompatibilidades propios de los mismos», en "Principios de derecho administrativo II», Servicio de publicaciones de la Facultad de Derecho (Universidad Complutense), 3. ${ }^{\text {a }}$ ed., Madrid, 1993, p. 206.; COSCULLUELA MONTANER, J.: «La posibilidad de anular las decisiones de la Administración por ser contrarias a Derecho, y la de condenar a la Administración a reparar los efectos de su actividad sobre los derechos e intereses por los ciudadanos, sitúan, realmente, en una posición de paridad ante la ley y el Derecho, a todos los sujetos jurídicos, incluida la Administración. Esta posibilidad última de control judicial representa, por tanto, la culminación de las garantías del ciudadano frente a la acción de la Administración.», en «Manual de Derecho Administrativo I», Ed. Civitas, 6. ${ }^{\text {a }}$ ed., Madrid, 1995, p. 477.; PAREJO ALFONSO, L., JIMÉNEZ-BLANCO, A. y ORTEGA ÁLVAREZ, L.: «Esta Ley, de gran calidad técnica — según unánime apreciación por la doctrina y la jurisprudencia - ha supuesto un enorme y definitivo progreso para el Derecho Administrativo, posibilitando su modernización (...), lo que vale decir su construcción conforme a las exigencias del Estado de Derecho. No puede sorprender, pues, que, salvo en algunos aspectos, este texto haya superado perfecta y airosamente la dura prueba de la Constitución de 1978.», en "Manual de Derecho Administrativo I», Ed. Ariel, 4. ${ }^{\text {a }}$ ed., Barcelona, 1996, p. 679. 
tal libertad de apreciación de la Administración, y el consiguiente riesgo de que se produjesen excesos en el amplio campo de actuación no sometido a control. Así, el artículo 40 de dicha Ley disponía que «No se admitirá recurso contencioso-administrativo respecto de los actos que se dicten en virtud de una ley que expresamente los excluya de la vía contencioso-administrativa».

Este precepto suponía una evidente reducción de las facultades de control contencioso de la discrecionalidad, puesto que el poder Ejecutivo quedaba, en definitiva, legitimado para determinar la posibilidad de que sus propios actos fuesen enjuiciados, lo que daba lugar a una injustificada superioridad del mismo en relación con los sujetos pasivos lesionados que, ante una relación aquejada de arbitrariedad, quedaban en una situación de total indefensión.

El contenido de este precepto habría de entenderse derogado por la disposición derogatoria tercera de la Constitución española, en la vía correspondiente a «cuantas disposiciones se opongan a lo establecido en la misma», puesto que la posibilidad de excluir del recurso contencioso-administrativo, la actuación de la Administración, a riesgo de que ésta fuese arbitraria, producía, claramente, una situación de indefensión proscrita por la Constitución española en su artículo 24, derecho fundamental concedido a todos los ciudadanos y que vincula, de acuerdo con el artículo 53.1, a todos los poderes públicos, y sin olvidar lo dispuesto en el artículo 106.1 con arreglo al cual los Tribunales controlan la potestad reglamentaria y la legalidad de la actuación administrativa, así como el sometimiento de ésta a los fines que la justifican

Si se toma en consideración la más acertada interpretación jurisprudencial elaborada a propósito de la anterior limitación, y teniendo en cuenta que la subsanación del derecho a la tutela judicial efectiva, como derecho procesal que es, se consigue mediante la oportuna restitución de la situación jurídica en la que se encontraban los particulares con anterioridad al perjuicio ocasionado, como consecuencia de la inobservancia de aquel derecho fundamental, así como al efectivo enjuiciamiento, si, en su caso, se tratase de un derecho material, entendemos que la competencia del Tribunal Constitucional para conocer del recurso de amparo, por violación de los derechos y libertades fundamentales, proclamada por el artículo 161.1 de la Norma Suprema, constituye una conquista definitiva en la lucha contra la arbitrariedad.

Un Juez ordinario, en el ejercicio de su función de juzgar y hacer ejecutar lo juzgado, entendería derogado el artículo 40 de la Ley Ju- 
risdiccional, sin que fuese precisa una previa declaración de inconstitucionalidad del mismo, puesto que los efectos de su aplicación caían en evidente contradicción con lo preceptuado por la Constitución a propósito del derecho a una tutela judicial plena ${ }^{25}$. Si esto era así para un Juez ordinario, tanto más lo sería para un Juez contencioso, por lo que, de la inaplicabilidad de la letra de la Constitución, podía, sin duda, desprenderse una clara manifestación de arbitrariedad judicial, que sería subsanada por el Tribunal Constitucional mediante el oportuno recurso de amparo.

Las zonas de inmunidad judicial en el ámbito de actuación de los poderes públicos se han visto reducidas, prácticamente, hasta la inexistencia. Así, el artículo 24 de la Ley Orgánica del Poder Judicial subraya la competencia de la Jurisdicción contencioso-administrativa, para conocer de los actos de los poderes públicos; el artículo 58.1 de la misma Ley entiende, como actos susceptibles de control por el Tribunal Supremo, los actos y disposiciones del Consejo General del Poder Judicial y los que se dicten en materia de personal, así como los actos de administración de órganos tales como el Congreso, el Senado, el Tribunal Constitucional, el Tribunal de Cuentas y el Defensor del Pueblo».

El definitivo éxito del control judicial de las actuaciones administrativas, sean regladas o discrecionales; de la elaboración, en el ámbito de actuación legislativo, de disposiciones normativas con rango de ley y de la interpretación y aplicación judicial de las mismas, lo constituye, sin lugar a dudas, el principio de interdicción de la arbitrariedad de los poderes públicos que la Norma Suprema garantiza en el párrafo tercero de su artículo noveno.

${ }^{25}$ Así lo ha entendido, explícitamente, la Sala cuarta del Tribunal Supremo, al manifestar, en sentencia de 3 de julio de 1979, que «no es necesario acudir a la tesis de la inconstitucionalidad sobrevenida, usada en algunas ocasiones en situaciones de transición, como la que atraviesa España al pasar de las viejas leyes fundamentales a la nueva Constitución, por cuanto el punto tercero de la disposición derogatoria de ésta deja sin efecto cuantas disposiciones se le opongan, y aunque es cierto que ello constituye una innovación en el Derecho Constitucional, no por ello puede dejar de reconocerse eficacia inmediata al citado texto derogatorio, cual lleva, como causa ésta obligada, la aplicación directa de la norma constitucional en todo cuanto ello sea necesario para que el ordenamiento jurídico español siga siendo el todo coherente y absoluto que se deduce del actual párrafo final del artículo $1^{\circ}$ del Código Civil, donde se impone a los Jueces y Tribunales el deber inexcusable de resolver en todo caso los asuntos de que conozcan, ateniéndose al sistema de fuentes establecido». 


\section{LA LEY 29/1998, REGULADORA DE LA JURISDICCIÓN CONTENCIOSO-ADMINISTRATIVA}

El Proyecto de la Ley reguladora de la Jurisdicción contenciosoadministrativa, remitido por el Gobierno socialista al órgano legislativo en el verano de 1995, pretendió, con éxito, la creación de Juzgados unipersonales de lo contencioso-administrativo, así como la conversión del recurso de apelación por el de casación ante Tribunal Supremo.

Un autorizado sector de la doctrina ${ }^{26}$ consideró, a propósito de este Proyecto, al que al propio tiempo se ha referido como «felizmente caducado», respecto del primer extremo, que «estos nuevos órganos judiciales plantean problemas sumamente serios: en primer término, la oportunidad de instaurar en esta materia órganos unipersonales y no colegiados, como hasta ahora se ha creído imprescindible para garantizar mejor en los juicios contra la Administración valores, tan esenciales a la Justicia, como la objetividad y la independencia; segundo y particularmente, ese refuerzo carecerá - aunque resulte sorprendente- de cualquier especialización en Derecho Administrativo y Tributario, especialización imprescindible, como se establece lúcidamente en la Ley de 1956 que creó la Jurisdicción actualmente existente y como ocurre en toda Europa, sin excepción alguna, incluso en la Inglaterra de la unidad jurisdiccional prototípica. En lo que respecta al segundo extremo, en opinión de este mismo sector de la doctrina ${ }^{27}$, el recurso de casación, es «infinitamente más inefectivo y formalista», por lo que la realización de esta vía "quebranta el principio común de la doble instancia, que también está generalizándose en Europa».

Ante la inminente aprobación, en Consejo de Ministros, del Anteproyecto de la Ley de la Jurisdicción contencioso-administrativa y la tramitación parlamentaria del Proyecto de Ley del Gobierno, muchos fueron los autores que coinciden en la ya asentada corriente doctrinal favorable a la fiscalización de los actos gubernamentales.

El anteproyecto de la Ley Jurisdiccional incluyó la creación, ante la consciente gravedad supuesta por la lentitud de la Justicia ${ }^{28}$, de

${ }^{26}$ GARCÍA DE ENTERRÍA, E., «Democracia, Jueces y control de la Administración», Ed. Civitas, Madrid, 1996, 2. a ed., p. 259.

${ }^{27}$ GARCÍA DE ENTERRÍA, E., «Democracia, Jueces y control de la Administración», Editorial Civitas, 2. edición, Madrid, 1996, p. 260.

${ }^{28}$ GARCÍA DE ENTERRÍA, E., al hacerse eco de este problema, concreta con total precisión lo siguiente: «En los últimos quince años se han multiplicado por seis los 
Juzgados unipersonales de lo contencioso-administrativo; pretensión ésta no compartida por los miembros de la Real Academia de las Ciencias Morales y Políticas.

El académico Enrique Fuentes Quintana, ante la alternativa de soluciones que procuren un mejor fin al problema planteado, propuso, a propósito del inmediato acontecimiento que suponía la esperada reforma de la Ley de 1956, incrementar el personal de las Salas, al entender que «el Juez solo, dentro de lo contencioso, parece que no es aconsejable. Por razones de eficacia y de perfeccionamiento jurídico, es mejor ampliar plantillas» ${ }^{29}$. El académico Jesús González Pérez, por su parte, planteó, al respecto, la posibilidad de «potenciar al ponente y simplificar el proceso» puesto que en el anteproyecto elaborado «únicamente hay un artículo que permite que, si media acuerdo entre las partes, haya demanda y contestación, pero no pruebas ni conclusiones», con lo que, «un litigante de mala fe», según este autor, «puede prolongar el proceso todo lo que él quiera».

En este contexto de pensadores partidarios del control de la legalidad de la actividad administrativa y de la debida garantía de los derechos e intereses legítimos de los ciudadanos frente a las extralimitaciones de la Administración, se promulgó la actual Ley 29/1998, de 13 de julio, reguladora de la Jurisdicción Contencioso-Administrativa, en cuya Exposición de Motivos queda delimitada, expresamente, la justificación de su propia existencia, que no es otra que la de «asegurar, en beneficio de los interesados y del interés general, el exacto sometimiento de la Administración al derecho en todas las actuaciones que realiza en su condición de poder público y en uso de las prerrogativas que, como tal, le corresponde.

Así, pues, esta Ley somete, al control de la Jurisdicción, la actividad de la Administración pública de cualquier clase que esté sujeta al Derecho Administrativo, articulando para ello las acciones procesales oportunas, crea los Juzgados de lo Contencioso-Administrativo, habida cuenta de la imprescindible y urgente necesidad de descongestión de los Tribunales de lo Contencioso-Administrativo, mediante la atribución, a aquellos órganos y a los Juzgados Centrales de lo Conten-

procesos contencioso-administrativos, mientras que el número de los Magistrados encargados de resolverlos sigue siendo sustancialmente el mismo (exactamente, los mismos ahora que los que se fijaron en la Ley de Planta Judicial de 28 de diciembre de 1988)», en «Democracia, Jueces y control de la Administración», cit., p. 257.

${ }^{29}$ Las consideraciones transcritas han sido tomadas del artículo, «La Justicia puede revisar todos los actos administrativos», E. Alonso y J.L. Lorente, ABC, Madrid, 17-8-1997, pp. 26 y 27. 
cioso-Administrativo, de un conjunto de competencias, que cubren un elevado número de los recursos que, cotidianamente, se interponen y elimina, en numerosos supuestos, la posibilidad de la doble instancia.

\section{LA ARBITRARIEDAD ADMINISTRATIVA EN EL ÁMBITO PENAL}

El delito de prevaricación de los funcionarios públicos se encuentra regulado en los artículo 404, dentro del capítulo I del Título XIX del Libro II del CP de 1995, título que lleva por rúbrica «Delitos contra la Administración Pública». Dispone el artículo $404 \mathrm{CP}$ que «a la autoridad o funcionario público que, a sabiendas de su injusticia, dictare una resolución arbitraria en un asunto administrativo se le castigará con la pena de inhabilitación especial para empleo o cargo público por tiempo de siete a diez años».

El delito de prevaricación de la autoridad o funcionario público, así tipificado, se integra por la infracción de un deber, debe de actuar conforme al ordenamiento jurídico del que la autoridad o funcionario es el garante y primer obligado, por ello, su actuación al margen y en contra de la Ley tiene un plus de gravedad que justifica el tipo penal. De alguna manera, el delito de prevaricación es el negativo del deber de los Poderes Públicos de actuar conforme a la Constitución Española y al ordenamiento jurídico, tal y como señala el artículo 9.1 con carácter general y que tiene su explícito mandado referente a la Administración Pública en el artículo 103 del Texto Fundamental. Y se ejerce arbitrariamente el poder cuando la autoridad o el funcionario dicta una resolución que no es afecta de una aplicación de la Constitución Española, sino pura y simplemente, producto de su libertad, convertida irrazonablemente en fuente de norma particular.

En cuanto a las concretas relaciones entre la Jurisdicción Contencioso-administrativa y la Jurisdicción Penal, debe tenerse en cuenta que el delito de prevaricación no trata de sustituir a la Jurisdicción Contencioso-administrativa en su labor genérica de control y verificación del sometimiento de la Administración al ordenamiento jurídico, sino que el propio campo de la respuesta penal es la sanción de supuestos límites reveladores de un abuso de poder. En definitiva, la Jurisdicción Contencioso-administrativa tiene por misión corregir la ilegalidad que pudiera cometer la Administración. El sistema penal, a través del delito de prevaricación administrativa trata de sancionar la arbitrariedad de la autoridad o funcionario público, lo que es un plus diferente de la mera ilegalidad. 
El delito de prevaricación tutela el correcto ejercicio de la función pública de acuerdo con los parámetros constitucionales que orientan su actuación. Garantiza el debido respeto, en el ámbito de la función pública, al principio de legalidad como fundamento básico de un Estado social y democrático de Derecho, frente a ilegalidades severas y dolosas, respetando coetáneamente el principio de intervención mínima del ordenamiento penal. Es por eso que no se trata de sustituir a la Jurisdicción Administrativa, en su labor de control de la legalidad de la actuación de la Administración Pública, por la Jurisdicción Penal a través del delito de prevaricación, sino de sancionar supuestos límite, en los que la actuación administrativa no sólo es ilegal, sino además injusta y arbitraria. De este modo el Derecho Penal solamente se ocupará de la sanción a los ataques más graves a la legalidad, constituidos por aquellas conductas que superan la mera contradicción con el Derecho para suponer un ataque consciente y grave a los intereses que precisamente las normas infringidas pretenden proteger.

El delito de prevaricación del artículo 404 pena al funcionario público que dicte una resolución injusta en asunto administrativo, a sabiendas de su ilegalidad e injusticia.

La evidencia de la injusticia ha de ser tan manifiesta que excluya la más leve duda en personas entendidas en derecho y prácticas administrativas. Se exigen, por tanto, dos elementos:

a) Uno de carácter objetivo, como es la existencia de una resolución arbitraria. La jurisprudencia viene subrayando que una resolución arbitraria no sólo ha de ser antijurídica o ilegal sino verdaderamente injusta, demostrativa de manera patente y clara del apartamiento más elemental de la función que al autor corresponde respetar por razón de su cargo, exigencia que se debe apreciar de manera más notoria en aquellos funcionarios o autoridades que son legos en derecho.

b) Otro subjetivo, que consiste en que el indicado autor de la resolución o resoluciones sabe que la misma es injusta, requisito que, dado su carácter intimista, ha de inferirse necesariamente de los datos objetivos señalados, siendo aquí donde debe entrar en juego el grado de error permisible según las circunstancias de cada caso y la medida de los indicados conocimientos jurídicos del sujeto activo de la acción.

En relación con la distinción entre el control de la Jurisdicción contencioso-administrativo y el control penal, nuestro Tribunal Supremo (Sala de lo Penal), en su Sentencia núm. 766/1999 de 18 mayo 
señala que en todo Estado constitucional inspirado en el principio clásico de división de poderes se establece un sistema de controles y contrapesos mutuos para garantizar la limitación del poder, el sometimiento de su ejercicio al ordenamiento jurídico y los derechos y libertades de los ciudadanos. Una manifestación de esta característica del Estado constitucional es el artículo 106 de la Constitución Española en el que se dice que «los Tribunales controlan la potestad reglamentaria y la legalidad de la actuación administrativa, así como el sometimiento de ésta a los fines que la justifican», precepto que residencia en los Tribunales el control para que la actuación de la Administración Pública se realice «con sometimiento pleno a la ley y al Derecho» tal como lo exige el artículo 103.1 del mismo Texto Legal. Este control, sin embargo, no está atribuido a todos los Tribunales indistintamente sino de forma exclusiva a los del orden contencioso-administrativo, a los que el artículo 24 de la Ley Orgánica del Poder Judicial declara competentes para conocer de las pretensiones que se deduzcan frente "a disposiciones de carácter general o a actos de las Administraciones Públicas españolas», así como «de las que se deduzcan en relación con actos de los Poderes públicos españoles de acuerdo con lo que dispongan las Leyes». En consecuencia, el control de legalidad de los actos de los órganos de la Administración Pública corresponde a los Juzgados y Tribunales del orden jurisdiccional contencioso-administrativo. Y este control no debe ser confundido con el enjuiciamiento por los Jueces y Tribunales del orden jurisdiccional penal de las personas que, ocupando o desempeñando las funciones propias de órganos de la Administración, incurren en conductas que revisten caracteres de delito. Los Jueces y Tribunales penales están llamados a juzgar a las autoridades y funcionarios que presuntamente hayan realizado un hecho penalmente típico, pero no lo hacen en el ejercicio de la función controladora establecida en el artículo 106.1 de la Constitución, sino en el ejercicio de la potestad jurisdiccional genérica que atribuye a todos los Jueces y tribunales el artículo 117.3 del Texto Fundamental. Los Jueces y Tribunales penales no controlan, pues, a la Administración Pública sino que, sencillamente, declaran cuando procede ejercer el «ius puniendi» del Estado contra la persona - autoridad, funcionario o ciudadano no investido de autoridad alguna- que se ha desviado en su comportamiento de la legalidad realizando un hecho penalmente típico.

La claridad teórica de la distinción que acaba de ser trazada - control de legalidad de la actuación administrativa por una parte, control de legalidad penal de la actuación de personas cualesquiera por otra- puede oscurecerse en la práctica cuando la ilegalidad de 
un acto administrativo supone, en quien o quienes lo han realizado, es decir, en el titular o los titulares del órgano administrativo que ha producido el acto, la comisión de un hecho en apariencia penalmente típico. Y el problema es especialmente delicado cuando el delito de que puede ser constitutivo el acto es, precisamente, un delito de prevaricación que está legalmente definido, desde un punto de vista objetivo, como el hecho de dictar un funcionario público una resolución injusta. Si la resolución injusta se identifica con la resolución contraria a la legalidad vigente, sea la legalidad sustantiva, sea la adjetiva, es evidente el riesgo de que quede difuminada la línea fronteriza entre el control de legalidad que debe ejercer la Jurisdicción contencioso-administrativa para que el ejercicio del poder ejecutivo y la actuación de la Administración se mantenga dentro del marco constitucionalmente establecido y el control de legalidad que, con respecto a todos los ciudadanos, debe ejercer la Jurisdicción penal. Llevando a sus últimas consecuencias dicha identificación, podría llegar a sostenerse que detrás de todo órgano administrativo que hubiese dictado un acto contrario a derecho habría una autoridad o funcionario autor de una resolución injusta que, de haberse dictado a sabiendas, habría de ser calificada como un delito de prevaricación. Pero éste es un resultado a que no debe llegarse por más de una razón. Entre otras, porque ni tendría sentido que en el sector administrativo del ordenamiento jurídico el derecho penal dejase de ser la última «ratio»para convertirse en la primera - dando al olvido en este ámbito el principio de «intervención mínima»-, ni es buena la judicialización de la vida política a que inevitablemente conduce la derivación hacia el orden jurisdiccional penal de cualquier enjuiciamiento que haya de hacerse en relación con la conducta observada por las autoridades y funcionarios en el ejercicio de sus cargos. Un claro indicio de que no puede ser confundida la ilegalidad administrativa con el delito de prevaricación lo tenemos en la enumeración que se hace en el art. 62 de la Ley 30/1992, de Régimen Jurídico de las Administraciones Públicas y del Procedimiento Administrativo Común, de los casos en que los actos de las Administraciones Públicas son nulos de pleno derecho. Encontramos en dicho precepto, por ejemplo, junto a los actos «que lesionan el contenido esencial de los derechos y libertades susceptibles de amparo constitucional», junto a los «dictados por órgano manifiestamente incompetente por razón de la materia o del territorio» y junto a los «dictados prescindiendo total y absolutamente del procedimiento legalmente establecido o de las normas que contienen las reglas esenciales para la formación de la voluntad de los órganos colegiados», a los «que sean constitutivos de infracción penal o se dicten como consecuencia de ésta», lo que parece indicar que para la ley 
es admisible la hipótesis de que un acto administrativo lesione el contenido esencial de un derecho fundamental, sea dictado por un órgano manifiestamente incompetente o producido prescindiendo por completo del procedimiento establecido - que son indudablemente supuestos de máxima ilegalidad-y que el acto en cuestión no sea, sin embargo, constitutivo de infracción penal.

De lo expuesto se deduce que no basta que una resolución administrativa sea contraria a derecho para que constituya un delito de prevaricación. Una resolución ilegal no es, sólo por ser ilegal, una resolución injusta. La injusticia supone un "plus» de contradicción con la norma que es lo que justifica la intervención del derecho penal. Únicamente cabe reputar injusta una resolución administrativa, a efectos de incardinarla en el tipo de prevaricación, cuando la ilegalidad sea evidente, patente, flagrante y clamorosa, tal y como viene sosteniendo la Jurisprudencia del Tribunal Supremo. El artículo 404 del Código Penal pone el acento en el elemento más objetivo y de fondo del «ejercicio arbitrario del poder» proscrito por el artículo 9.3 de la Constitución Española. Y se ejerce arbitrariamente el poder, cuando el funcionario dicta una resolución que no es efecto de la Constitución y del resto del ordenamiento jurídico - a los que están sujetos tanto los poderes públicos como los ciudadanos según el citado artículo 9.1 de la Constitución- sino, pura y simplemente, de su capricho, de su voluntad convertida irrazonablemente en aparente fuente de normatividad. Cuando se actúa así y el resultado es una injusticia, es decir, una lesión del mejor derecho - si la resolución ha de reconocerlo a uno u otro ciudadano- o del interés colectivo - si es éste el que está en juego- se «pone» el elemento objetivo de la prevaricación. Y como el elemento subjetivo viene legalmente expresado con la locución «a sabiendas», que elimina del tipo tanto la comisión por culpa como por dolo eventual, se puede decir, en resumen, que se comete el delito de prevaricación previsto en el artículo 404 del Código penal cuando la autoridad o funcionario, teniendo plena conciencia de que resuelve al margen del ordenamiento jurídico y de que ocasiona un resultado materialmente injusto, actúa de tal modo porque quiere este resultado y antepone el contenido de su voluntad a cualquier otro razonamiento o consideración. 